\title{
Adjustment of brood care behaviour in the absence of a mate in two species of Nicaraguan crater lake cichlids
}

\author{
Topi K. Lehtonen • Bob B. M. Wong • \\ P. Andreas Svensson • Axel Meyer
}

\begin{abstract}
In many taxa, parental strategies can vary among individuals. This is especially true in species with biparental care, with males, more often than females, deserting their mates. While there is an abundance of theoretical predictions and empirical data on factors inducing mate abandonment by males, much less is known about what consequences this may have on female behaviour, particularly in the field and in non-avian systems. Here, we compared brood defence rate, behavioural defence types, and brood success of solitary and paired females in two species of Neotropical cichlid fish in their natural habitat. In terms of the rate of territorial aggression towards potential brood predators, solitary females were able to fully compensate in the absence of a male but, in so doing, ended up maintaining smaller territories, which appeared to compromise offspring fitness in at least one of the two species. Hence, our results suggest that even extensive quantitative compensation in parental effort by solitary females may not be enough to ensure adequate qualitative compensation for the lack of male participation, highlight-
\end{abstract}

\section{T. K. Lehtonen A. Meyer}

Lehrstuhl für Zoologie und Evolutionsbiologie,

Department of Biology, University of Konstanz,

78457 Constance, Germany

T. K. Lehtonen • B. B. M. Wong • P. A. Svensson

School of Biological Sciences, Monash University,

Victoria 3800, Australia

Present Address:

T. K. Lehtonen $(\bowtie)$

Section of Ecology, Department of Biology,

20014 University of Turku,

Turku, Finland

e mail: topi.lehtonen@utu.fi ing the importance of distinguishing between these two aspects of compensatory parental care.

Keywords Mate desertion · Midas cichlid species complex · Offspring survival · Parental care $\cdot$ Qualitative care compensation $\cdot$ Territorial aggression

\section{Introduction}

Monogamous behaviour is often associated with biparental care for offspring (Smith and Wootton 1995; Reynolds 1996). Accordingly, environmental and social conditions that tend to increase the relative fitness benefits of polygyny may also promote the desertion of offspring by males (Smith and Wootton 1995; Gross 2005). The environmental context that influences the probability of offspring survival could also determine whether a female should continue caring for her brood after she has been deserted (Lazarus 1990). Evidence, however, suggests that deserted females often stay with their offspring (McNamara et al. 2002). Moreover, in most biparental species mate desertion is much more commonly documented in males than in females (for notable examples of species in which either sex is just as likely to desert as the other, see Bessinger and Snyder 1987; Griggio and Pilastro 2007).

The resulting sexual conflict over parental care has attracted considerable interest from biologists (e.g. Clutton-Brock and Vincent 1991; Queller 1997; McNamara et al. 1999; Kokko and Jennions 2008). A common approach to tackling this topic is to experimentally decrease the level of male participation in parental care activities, and then monitor the female's response under controlled laboratory conditions (Houston et al. 2005). However, field-based studies are crucial if we want to understand how solitary females might 
compensate for the absence of male input in offspring care under ecologically relevant settings. In one such study, solitary Spanish sparrow (Passer hispaniolensis) females were found to invest greater effort into offspring provisioning compared with paired females but were still unable to attain a provisioning rate comparable to the combined effort of paired females and their mates (Marques 2004). In general, much of what we currently know about brood care compensation has come almost exclusively from studies on birds (reviewed in Harrison et al. 2009). By contrast, our understanding of this phenomenon in other taxa is less well developed.

Furthermore, previous studies of mate desertion have typically focussed only on changes in the amount of care whilst overlooking potential effects on the quality of care being given. For example, in bird studies, usually only feeding rates have been measured without taking into account the quality, or even quantity, of food being brought to the nest (Harrison et al. 2009). The latter could be important if, for example, there is a trade-off between quantitative and qualitative components of parental compensation. Hence, one should not assume, a priori, a positive correlation between these two aspects of care (i.e. quantity versus quality). More broadly, assessing only one, whilst ignoring the other, could bias our understanding of the consequences of mate desertion. Accordingly, in this field-based study, we used a non-avian study system (see 'Methods') to examine to what extent single females are able to adjust their offspring defence behaviour after their mates are no longer present and to distinguish between quantitative and qualitative aspects of compensatory care.

\section{Methods}

Our field-based study was carried out on two species of cichlid fish endemic to the crater lakes of Nicaragua, Central America: Amphilophus sagittae from Lake Xiloá (Stauffer and McKaye 2002; Elmer et al. 2009) and the arrow cichlid, Amphilophus zaliosus, from Lake Apoyo (Barlow and Munsey 1976; Barluenga et al. 2006). Several features of the biology of these two species make them particularly well suited for investigating differences in parental care behaviours between solitary and paired females. Both species belong to the Midas cichlid complex (Elmer et al. 2010), members of which were previously thought to be strictly monogamous and biparental (McKaye 1977; Rogers 1987, 1988; Barlow 2000), but have recently been found to also engage in female-only care under natural conditions (Lehtonen et al. 2010b). Like other members of this species complex, A. sagittae and A. zaliosus have a prolonged breeding season and establish stationary breeding territories (Barlow 1976; McKaye 1977; Rogers 1987; Barlow 2000), making them highly amenable to field observations. The free-swimming fry of these fish are independent enough to feed on their own by catching planktonic organisms (Barlow 1976) and, occasionally, grazing on mucus from the sides of their parents (Noakes and Barlow 1973; personal observation). Offspring, however, rely on their parents to defend them against conspecific and heterospecfic predators (Barlow 1976; Rogers 1987; McKaye and Murry 2008; Lehtonen et al. 2010a), and success in defence behaviours is critical to parental fitness (McKaye 1977; Rogers 1987, 1988; Barlow 2000). In this regard, both the quantity (i.e. rate of aggressive response) and quality of care (i.e. reaction distance and kinds of aggressive behaviours, see below for details) are likely to be important.

All observations were conducted between December 2007 and January 2008 at depths between 3.5 and $18 \mathrm{~m}$ using SCUBA. To address the question of female responses to mate desertion, we compared total work rate and other aspects of brood defence behaviour of naturally occurring solitary and paired females for $A$. sagittae $\left(n_{\text {single }}=5, n_{\text {paired }}=21\right)$ and arrow cichlids $\left(n_{\text {single }}=14, n_{\text {paired }}=15\right)$, and examined age distributions of the broods guarded by the two female types (i.e. solitary versus paired). The proportions of solitary and paired females included in the study reflected the frequency in which they were observed in the field (see Lehtonen et al. 2010b). Parental behaviour was assessed in relation to all but one of the arrow cichlid broods encountered during the course of the study. A. sagittae broods were chosen at random within the subset of encountered broods that were not older than 3 weeks (approximated age) in order to match brood ages of the two species as closely as possible. Because the likelihood of male desertion should increase with increasing survival prospects of the offspring (Smith and Wootton 1995; Gross 2005), it is reasonable to expect that solitary females would be guarding offspring that are older, and therefore larger, than average. However, if offspring survival of solitary females is clearly lower than that of paired females, we would expect to see the opposite pattern.

We adopted a sampling protocol that was successfully applied in an earlier study (Lehtonen et al. 2010a). Specifically, after a breeding territory was located, the observer swam to within approximately $2 \mathrm{~m}$ of the territory, taking care not to interrupt the parents or any neighbouring cichlid broods. The date, water depth, and female status (solitary or paired) were recorded. For most of the territories (Table 1), we also approximated total length of the female and age of free-swimming young (beginning at 'age 0' for juveniles that had just started to swim). These age estimations were based on the apparent size of juveniles, and were calibrated against our previous observations on growth rates both in nature and the laboratory. In addition, the activities of the parental fish were recorded for $15 \mathrm{~min}$ after an acclimatisation period of a minimum of 
Table 1 Total length and brood age of solitary and paired females

Values are gives as mean \pm standard error of the mean

\begin{tabular}{|c|c|c|c|c|c|}
\hline \multirow[t]{2}{*}{ Species } & \multirow[t]{2}{*}{ Female status } & \multicolumn{2}{|c|}{ Total length $(\mathrm{cm})$} & \multicolumn{2}{|c|}{ Brood age (weeks) } \\
\hline & & Mean & $n$ & Mean & $n$ \\
\hline \multirow[t]{2}{*}{ A. sagittae } & Solitary & $21 \pm 0.7$ & 5 & $0.68 \pm 0.14$ & 5 \\
\hline & Paired & $21 \pm 0.5$ & 15 & $1.40 \pm 0.18$ & 20 \\
\hline \multirow[t]{2}{*}{ Arrow cichlid } & Solitary & $22 \pm 0.6$ & 14 & $1.00 \pm 0.14$ & 14 \\
\hline & Paired & $22 \pm 0.6$ & 15 & $0.68 \pm 0.16$ & 13 \\
\hline
\end{tabular}

$3 \mathrm{~min}$. Each act of territory defence behaviour by the parent fish was classified according to one of the following three categories: 'displays' (flared fins or gills with gradual or no movement towards the fish invading the territory), 'attacks' (rapid movement towards the intruder until it fled) and 'chase' (an attack that was continued even after the intruder had started to flee). We consider it likely that these behavioural responses differ both in terms of costliness and effectiveness, with displays having the lowest level of expenditure and impact, and chases having the highest. For each of the three aggressive acts, we also noted the reaction distance, measured from the centre of the territory, as an approximation of territory size. For displays and attacks, this was estimated as the distance between the (approximated) centre of the brood and the invading fish at the time of the response. For chases, we approximated the distance between the centre of the brood and the parent at the end of the chase.

Using the above data, we were able to assess (1) the total rate (quantity) of offspring defence (analysed as the sum of all displays, attacks and chases taking place within the 15-min observation period), (2) the quality of offspring defence in terms of reaction distances and relative frequencies of the three aggression categories (display, attack and chase) and (3) female success in brood defence as estimated from the 'age score' given to each brood (using data from all broods sampled across the entire breeding season). The total rate of offspring defence was analysed using linear models with species (Arrow cichlid or A. sagittae), status (single or paired) and their two-way interaction as predictor variables. Count data were square root transformed to satisfy normality, and $t$ tests were used to test parameter estimates. In addition, we also analysed whether the total work rate differed between single females and pairs (with the latter based on the collective effort observed for both the male and female in the pair). To investigate whether the type of aggression differed between single and paired females, we analysed the counts of the three aggressive behaviours in a linear mixed model. This model was fitted by maximizing the log-likelihood, with species, status and aggression category as fixed factors, and the identity of the territory as a random factor. Non-significant terms were removed following model simplification using likelihood ratio tests ( $G^{2}$ with $\alpha=0.05$, Crawley 2007). We then proceeded to test whether the relative frequencies of the three aggression categories differed between single and paired females. This was done by analysing the counts of all three types in a paired fashion (i.e. display vs. attack, display vs. chase and attack vs. chase), using generalized mixed models with a binomial error and a logit link function. Each comparison had the binomial occurrence of two of the aggression types as the response variable, status and species as a fixed factors, and territory as a random factor. Three models were each fitted using one of the three possible comparisons (display vs. attacks, display vs. chase and attack vs. chase). This procedure is equivalent to performing a multinomial (trinomial) analysis, but is easier to interpret. Model simplification was done using $\chi^{2}$ tests (Crawley 2007). Finally, to assess differences in the reaction distance (proxy of territory size), female total length and fry age (log transformed) between solitary and paired individuals, we performed analyses of variance (ANOVAs), initially using observation date as a covariate. However, because the effect of observation date was, in all cases, non-significant, it was subsequently removed from analyses. ANOVAs were conducted using Systat 12 (SPSS Inc.) software, and for the rest of the analyses we used $R$ 2.8.0 (R Development Core Team).

\section{Results}

Rate of offspring defence (quantity of care)

Solitary and paired females did not significantly differ in body size in either of the two species (Tables 1 and 2). Therefore, we did not include body size as a covariate in any of the remaining analyses. There was no significant interaction between species and status in the total number (per $15 \mathrm{~min}$ ) of aggressive behaviours $\left(F_{1,51}=0.362, p=0.55\right)$. A model fitted without the interaction showed a significant effect of status $\left(t_{52}=3.65, p<0.001\right)$ but not of species $\left(t_{52}=0.512\right.$, $p=0.61$ ) on total aggression. In other words, solitary females exhibited a higher total rate of aggressive defence behaviours than paired females in both species (Fig. 1). When the contribution by the males were included in the analysis, there was no longer any effect of status on the number of 
Table 2 Results of the two factor ANOVAs

\begin{tabular}{lllc}
\hline Comparison & Effect & Test statistic & $p$ value \\
\hline Female size & Status & $F_{1,45}=0.213$ & 0.65 \\
& Species & $F_{1,45}=0.779$ & 0.38 \\
& Status $\times$ species & $F_{1,45}=0.372$ & 0.55 \\
Reaction distance & Status & $F_{1,51}=16.2$ & $<0.001$ \\
& Species & $F_{1,51}=0.067$ & 0.80 \\
& Status $\times$ species & $F_{1,51}=0.268$ & 0.61 \\
Brood age & Status & $F_{1,48}=0.036$ & 0.85 \\
& Species & $F_{1,48}=2.02$ & 0.16 \\
& Status $\times$ species & $F_{1,48}=4.31$ & 0.043 \\
\hline
\end{tabular}

'Status' effect refers to whether the female was 'solitary' or 'paired'

aggressive behaviours $\left(t_{52}=1.28, p=0.21\right)$. This means that single females fully compensated for the lack of male participation by performing aggressive behaviours at levels similar to the combined efforts of male-female pairs (Fig. 1).

\section{Quality of offspring defence}

With regard to the three aggression categories (i.e. display, attack and chase), there was no significant three-way interaction between species, status and aggression category $\left(G^{2}=1.98, p=0.37\right)$, and no significant interaction between species and status $\left(G^{2}=0.467, p=0.49\right)$. However, there were significant interactions between aggression category and status $\left(G^{2}=19.0, p<0.001\right)$, as well as between aggression category and species $\left(G^{2}=18.2, p<0.001\right)$. In other words, the frequency of the three aggressive behaviours differed between single and paired females, as well as between the two species.

To examine what was driving these two interactions, the relative frequencies of the three aggression types were explored using binomial mixed models. None of the resulting models showed significant interactions between status and species (all $\chi^{2}<3.52, p>0.05$ ), so they were refitted without these terms. The reduced models revealed that, compared with singe females, paired females performed more chases relative to displays $(z=2.63, p=0.009)$ and more chases relative to attacks $(z=2.51, p=0.012$, Table 3$)$. However, the number of displays relative to attacks was not affected by female status $(z=0.505, p=0.61)$. The two species did not differ in the relative frequency of chases to displays $(z=1.25, p=0.21)$ or chases to attacks $(z=1.62$, $p=0.11$ ). However, arrow cichlids performed more attacks relative to displays compared with $A$. sagittae, regardless of female status (species: $z=4.43, p<0.001$; Table 3 ).

Reaction distances towards approaching predators were shorter for solitary than paired females (Fig. 2; Table 2) in both species (Fig. 2; Table 2).

\section{Success in offspring defence}

Both species considered, the age of offspring guarded by solitary females was not different from that of paired females (Tables 1 and 2). However, in the case of $A$. sagittae, over the whole breeding season, juveniles guarded by single females were smaller than those of paired females (Tables 1 and 2; post hoc $t$ test: $t_{23}=2.21$, $p=0.038$ ).

\section{Discussion}

Earlier studies, mostly on birds, have indicated that when females adjust their workload following decreased male participation in parental care, they are able (or willing) to only partially compensate their provisioning rate in the absence of a partner (Houston et al. 2005; Harrison et al. 2009). In contrast, this study shows that solitary female cichlid fish were able to fully compensate for the absence of a partner in regard to the rate of aggressive responses towards potential offspring predators. Specifically, we found that solitary females attained approximately as high a response rate as that observed in paired fish (i.e. based on the collective effort observed for both the male and female in the pair). However, despite this extensive quantitative compensation in work rate, solitary females were not able to provide the same quality of care as that provided by paired females and their mates. In particular, we found that
Fig. 1 The total rate of aggressive responses towards potential brood predators. The white columns indicate female (either single or paired) total aggression rate and male participation is marked with black. Error bars of 'pairs' refer to the combined effort of both sexes. Sample sizes are given above each column

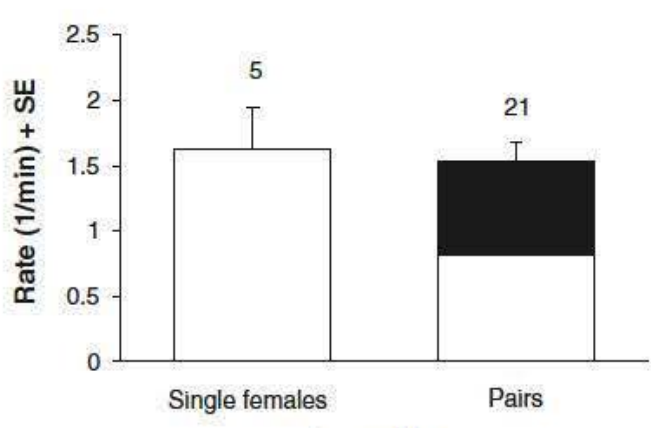

A. sagittae

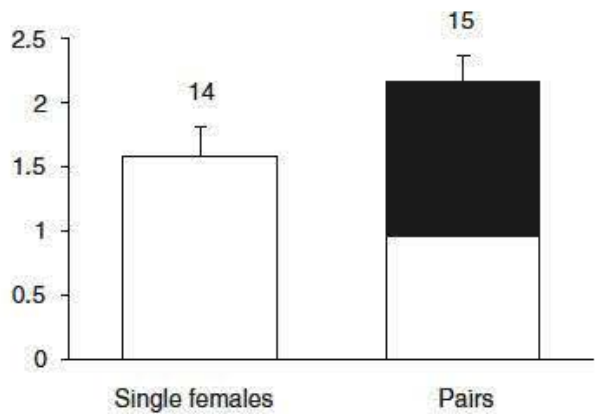

Arrow cichlid 
Table 3 Distributions of the three different aggression categories in single and paired females, represented both as a rate (aggression events/min) and relative frequency $(\%)$

Sample sizes for single and paired females were five and 21 for A. sagittae and 14 and 15 for arrow cichlids, respectively. All values are gives as mean $\pm \mathrm{SE}$

\begin{tabular}{|c|c|c|c|c|c|}
\hline \multirow[t]{3}{*}{ Species } & \multirow[t]{3}{*}{ Aggression type } & \multicolumn{4}{|l|}{ Status } \\
\hline & & \multicolumn{2}{|l|}{ Single } & \multicolumn{2}{|l|}{ Paired } \\
\hline & & Rate & Frequency & Rate & Frequency \\
\hline \multirow[t]{3}{*}{ A. sagittae } & Display & $0.52 \pm 0.06$ & $36 \pm 6.1$ & $0.30 \pm 0.04$ & $43 \pm 5.4$ \\
\hline & Attack & $0.99 \pm 0.26$ & $58 \pm 4.3$ & $0.40 \pm 0.06$ & $45 \pm 4.7$ \\
\hline & Chase & $0.12 \pm 0.06$ & $5.6 \pm 2.8$ & $0.12 \pm 0.04$ & $12 \pm 3.4$ \\
\hline \multirow[t]{3}{*}{ Arrow cichlid } & Display & $0.39 \pm 0.06$ & $25 \pm 2.9$ & $0.15 \pm 0.04$ & $18 \pm 4.3$ \\
\hline & Attack & $1.10 \pm 0.16$ & $71 \pm 3.3$ & $0.69 \pm 0.12$ & $71 \pm 4.2$ \\
\hline & Chase & $0.07 \pm 0.03$ & $3.9 \pm 1.5$ & $0.11 \pm 0.03$ & $11 \pm 2.9$ \\
\hline
\end{tabular}

single females of both species exhibited shorter reaction distances and used less aggressive/costly brood defence behaviours (indicated by a low incidence of chases) than paired females. Defending a smaller area or being unable to leave the brood to chase away predators that pose the greatest threat can severely handicap the quality of brood defence. Hence, our findings underscore the importance of considering whether females can compensate for the quality, as well as quantity, of care, with the former having been largely neglected by the main body of studies in this field (Harrison et al. 2009).

In $A$. sagittae, the average size of juveniles defended by solitary females was smaller than that defended by paired females, as measured over the whole breeding season. Offspring of solitary females may simply not survive as well as those of paired females, due to the challenges solitary females face when trying to defend the brood against offspring predators. However, we cannot rule out the possibility that the fry of solitary females may also be growing at a slower rate due to impeded feeding. Even though cichlids do not directly capture food for their young, single $A$. saggitae females may be less efficient at guiding young to food within their (smaller) territory or to provide enough mucous for their offspring to graze.

In contrast to the patterns observed for A. saggitae, we did not find any differences in the average brood size of

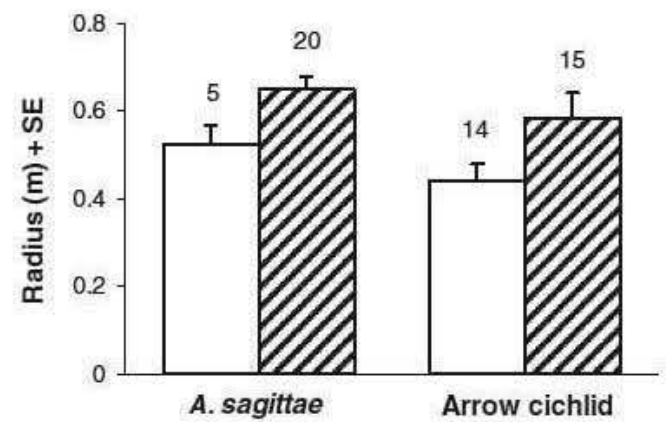

Fig. 2 Radius of breeding territories defended by females. White columns indicate single females and hatched columns paired females. Sample sizes are also given solitary versus paired females in the arrow cichlid (A. zaliosus). We propose that this is due to interspecific differences in survivorship of the broods of paired females. At the time of the study (breeding season of 2007-2008), arrow cichlid broods seemed to have a very low-survival rate (irrespective of the status of the female), while $A$. sagittae broods had a higher general survivorship (Lehtonen, McCrary and Meyer, unpublished manuscript). Furthermore, field studies conducted on other Neotropical cichlids have shown that males generally do not abandon the brood until after the juveniles have reached the free-swimming stage (e.g. Wisenden 1994; Jennions and Polakow 2001; Vélez et al. 2002; personal observations in Nicaragua). Hence, we would not expect differences in brood survival between the two female categories until the juveniles have already been free-swimming for several days.

Why should solitary cichlid females show a greater quantitative compensation for the lack of a mate than females of most other animals studied to date (Houston et al. 2005; Smiseth et al. 2005; Harrison et al. 2009; Suzuki and Nagano 2009)? One possibility is that previous studies have mostly focused on brood incubation and food provisioning, whereas if solitary cichlid females were not compensating their rate of brood defence so extensively, their offspring might have extremely low-survival prospects due to the high rate of predation and breeding territory competition (McKaye 1977; Rogers 1988). Furthermore, the relationship between offspring number and costs of parental care are likely to be different in fishes as compared with birds or, indeed, many other animal groups (e.g. Lazarus and Inglis 1986; Wisenden 1999; Rauter and Moore 2004). However, more research, preferably across a range of taxa, would be needed to assess how the costbenefit dynamics of care affect the quantitative aspects of care compensation provided by single females.

As the non-invasive approach of this study did not allow experimental removal of males for ethical and practical reasons, it may seem possible that single females included in the study represented a non-random subset of females in the population. However, we consider it very unlikely that 
the 'quality' of solitary females was significantly biased or, indeed, that any such bias could explain the observed patterns in brood defence. Firstly, we found no significant difference in body size between solitary and paired females. This is important because body size is known to correlate with measures of quality in Neotropical cichlids, especially in regard to egg number and parental care (McKaye 1986; Wisenden 1995; Barlow 2000). Secondly, contrary to what should be expected if single and paired females differed in quality, shifts in the behaviour of the former did not consistently indicate lower (short response distances, a low prevalence of chases) or higher (high rate of aggressive responses) than average quality. Hence, our results suggest that solitary females modified their behaviour in order to cope with the altered demands of offspring care rather than any attributes of their intrinsic quality per se.

In conclusion, the results of this study show that when females are left to care for their offspring on their own, even a full compensation in parental work rate does not necessarily match the quality of care paired females are able to perform in conjunction with their mates. Our study therefore underscores the importance of considering not only quantitative but also qualitative aspects of care compensation.

Acknowledgements We thank L. López and J. McCrary (FUN DECI/GAIA) for logistical support in Nicaragua, M. Geiger for his assistance on many of the dives and for helping to sink 'Flor de Caña' between them, R.I. Membreño Andino and M. E. Bernal for additional help in the field, D. Heg, O. Svensson and an anonymous reviewer for helpful comments on the manuscript, and MARENA (Nicaragua) for issuing the requisite work permits. Financial support was provided by the Alexander von Humboldt Foundation of Germany and the Academy of Finland (TKL), the Australian Research Council (BBMW, PAS) and the Deutsche Forschungsgemeinschaft (AM). The study complies with all the current laws of Nicaragua.

Conflicts of interest The authors declare that they have no conflict of interest.

\section{References}

Barlow GW (1976) The Midas cichlid in Nicaragua. In: Thorson TB (ed) Investigations of the Ichthyofauna of Nicaraguan Lakes. University of Nebraska Press, Nebraska, pp 333358

Barlow GW (2000) Cichlid fishes: nature's grand experiment in evolution. Perseus Publishing, Cambridge

Barlow GW, Munsey JW (1976) The red devil Midas arrow cichlid species complex in Nicaragua. In: Thorson TB (ed) Investiga tions of the Ichthyofauna of Nicaraguan Lakes. University of Nebraska Press, Nebraska, pp 359369

Barluenga M, Stölting KN, Salzburger W, Muschick M, Meyer A (2006) Sympatric speciation in Nicaraguan crater lake cichlid fish. Nature 439:719 723. doi:10.1038/nature04325

Bessinger SR, Snyder NFR (1987) Mate desertion in the snail kite. Anim Behav 35:477 487. doi:10.1016/S0003 3472(87)80273 7
Clutton Brock TH, Vincent ACJ (1991) Sexual selection and the potential reproductive rates of males and females. Nature 351:58 60. doi: $10.1038 / 351058 \mathrm{a} 0$

Crawley MJ (2007) The R book. Wiley, Chichester

Elmer KR, Lehtonen TK, Meyer A (2009) Color assortative mating contributes to sympatric divergence of neotropical cichlid fish. Evolution 63:2750 2757. doi:10.1111/j.1558 5646.2009.00736.x

Elmer KR, Kusche H, Lehtonen TK, Meyer A (2010) Local variation and parallel evolution: morphological and genetic diversity across a species complex of Neotropical crater lake cichlid fishes. Philos Trans R Soc B 365:1763 1782. doi:10.1098/rstb.2009.0271

Griggio M, Pilastro A (2007) Sexual conflict over parental care in a species with female and male brood desertion. Anim Behav 74:779 785. doi:10.1016/j.anbehav.2007.01.007

Gross MR (2005) The evolution of parental care. Q Rev Biol 80:37 45. doi:10.1086/431023

Harrison F, Barta Z, Cuthill I, Székely T (2009) How is sexual conflict over parental care resolved? A meta analysis. J Evol Biol 22:1800 1812. doi:10.1111/j.1420 9101.2009.01792.x

Houston AI, Székely T, McNamara JM (2005) Conflict between parents over care. Trends Ecol Evol 20:33 38. doi:10.1016/j. tree.2004.10.008

Jennions MD, Polakow DA (2001) The effect of partial brood loss on male desertion in a cichlid fish: an experimental test. Behav Ecol 12:84 92

Kokko H, Jennions MD (2008) Parental investment, sexual selection and sex ratios. J Evol Biol 21:919 948. doi:10.1111/j.1420 9101.2008.01540.x

Lazarus J (1990) The logic of mate desertion. Anim Behav 39:672 684. doi:10.1016/S0003 3472(05)80378 1

Lazarus J, Inglis IR (1986) Shared and unshared parental investment, parent offspring conflict and brood size. Anim Behav 34:1791 1804. doi:10.1016/S0003 3472(86)80265 2

Lehtonen TK, McCrary JK, Meyer A (2010a) Territorial aggression can be sensitive to the status of heterospecific intruders. Behav Process 84:598 601. doi:10.1016/j.beproc.2010.02.021

Lehtonen TK, Wong BBM, Lindström K, Meyer A (2010b) Species divergence and seasonal succession in rates of mate desertion in closely related Neotropical cichlid fishes. Behav Ecol Socibiol. doi:10.1007/s0026501010616

Marques PAM (2004) Parental care, male desertion, and reproductive success in the Spanish sparrow, Passer hispaniolensis. Zool Stud 43:123 131

McKaye KR (1977) Competition for breeding sites between the cichlid fishes of Lake Jiloa, Nicaragua. Ecology 58:291 302. doi:10.2307/1935604

McKaye KR (1986) Mate choice and size assortative pairing by the cichlid fishes of Lake Jiloá, Nicaragua. J Fish Biol 29(Supple ment A):135 150. doi:10.1111/j.1095 8649.1986.tb05005.x

McKaye KR, Murry BA (2008) Sex role differentiation in brood defense by a Nicaraguan cichlid fish, Amphilophus xiloanensis. Caribb J Sci 44:13 20

McNamara JM, Gasson CE, Houston AI (1999) Incorporating rules for responding into evolutionary games. Nature 401:368 371 . doi: $10.1038 / 43869$

McNamara JM, Houston AI, Székely T, Webb JN (2002) Do parents make independent decisions about desertion? Anim Behav 64:147 149. doi: $10.1006 /$ anbe. 2002.3038

Noakes DLG, Barlow GW (1973) Ontogeny of parent contacting in young Cichlasoma citrinellum (Pisces, Cichlidae). Behaviour 46:221 255. doi:10.1163/156853973X00021

Queller DC (1997) Why do females care more than males? Proc R Soc Lond B 264:1555 1557. doi:10.1098/rspb.1997.0216

Rauter CM, Moore AJ (2004) Time constraints and trade offs among parental care behaviours: effects of brood size, sex and loss of mate. Anim Behav 68:695 702. doi:10.1016/j.anbehav.2003.09.018 
Reynolds JD (1996) Animal breeding systems. Trends Ecol Evol 11:68 72. doi:10.1016/0169 5347(96)81045 7

Rogers W (1987) Sex ratio, monogamy and breeding success in the Midas cichlid (Cichlasoma citrinellum). Behav Ecol Sociobiol 21:47 51. doi:10.1007/BF00324434

Rogers W (1988) Parental investment and division of labor in the Midas cichlid (Cichlasoma citrinellum). Ethology 79:126 142

Smiseth PT, Dawson C, Varley E, Moore AJ (2005) How do caring parents respond to mate loss? Differential response by males and females. Anim Behav 69:551 559. doi:10.1016/j.anbehav.2004.06.004

Smith C, Wootton RJ (1995) The costs of parental care in teleost fishes. Rev Fish Biol Fisher 5:7 22. doi:10.1007/BF01103363

Stauffer JR Jr, McKaye KR (2002) Descriptions of three new species of cichlid fishes (Teleostei: Cichlidae) from Lake Xiloá, Nicaragua. Cuadernos de la Investigación de la UCA $12: 1 \quad 18$
Suzuki S, Nagano M (2009) To compensate or not? Caring parents respond differentially to mate removal and mate handicapping in the burying beetle, Nicrophorus quadripunctatus. Ethology 115:1 6. doi:10.1111/j.1439 0310.2008.01598.x

Vélez MJ, Jennions MD, Telford SR (2002) The effect of an experimental brood reduction on male desertion in the Panama nian blue acara cichlid Aequidens coeruleopunctatus. Ethology 108:331 340. doi:10.1046/j.1439 0310.2002.00772.x

Wisenden BD (1994) Factors affecting mate desertion by males in free ranging convict cichlids (Cichlasoma nigrofasciatum). Behav Ecol 5:439 447. doi:10.1093/beheco/5.4.439

Wisenden BD (1995) Reproductive behaviour of free ranging convict cichlids, Cichlasoma nigrofasciatum. Environ Biol Fish 43:121 134. doi:10.1007/BF00002480

Wisenden BD (1999) Alloparental care in fishes. Rev Fish Biol Fisher 9:45 70. doi:10.1023/A:1008865801329 